\title{
Violence against Health Care Professionals and Facilities-Local Insights about a Global Malady
}

\author{
${ }^{1}$ Department of Medico Legal, Medicos Legal Action Group Trust, \\ Chandigarh, India \\ ${ }^{2}$ Department of Cornea, Sankara Netralaya Hospital, Chennai, \\ Tamil Nadu, India \\ ${ }^{3}$ Department of Radiology, Sri Guru Ram Das Institute of Medical \\ Sciences \& Research, Amritsar, Punjab, India \\ ${ }^{4}$ Department of Oncology, Shalby Cancer \& Research Institute, \\ Mumbai, Maharashtra, India
}

Neeraj Nagpal ${ }^{1}$ Nimisha Nagpal ${ }^{2} \quad$ Nilanshu Kataria $^{3} \quad$ Purvish Parikh $^{4}$

Address for correspondence Neeraj Nagpal, Managing Trustee, Medicos Legal Action Group, Trust, SCO 1066, Sector 123, Mohali 140301, Chandigarh, India (e-mail: hopeclinics@yahoo.com).

South Asian J Cancer 2021;9:257-260.

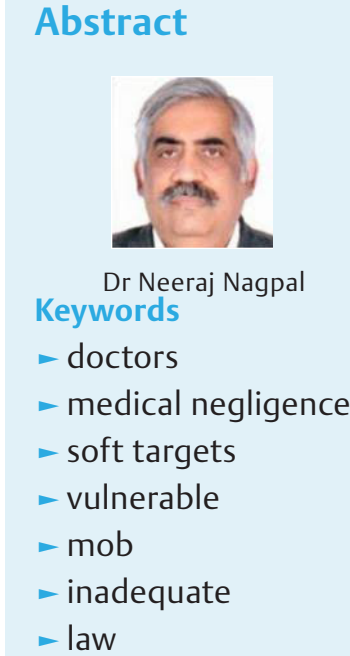

Acts of violence against health care professionals (especially doctors) as well as facilities are a growing global problem. In our country, it has taken an unfortunate dramatic turn of the involvement of a mob-a ragtag group of persons who organize and perpetrate the crime based on community, caste, religion, or political affiliations. This crucial factor is the fundamental difference in what we face as compared with the so-called Yi Nao phenomenon of China. In India, the mob gathers and indulges in acts of violence, intimidation, and blackmail at the behest of its "leader," often having no direct relationship with the deceased patient. It is premeditated and systematic vandalism. Often it is also associated with financial gain to the perpetrators through extortion and blackmail, adding to the woes of the health care professionals and hospital facility. We discuss what is the primary goal and what is a byproduct in this cycles of violence against the people who are doing their best to save the lives of patients. Unless the governments and the courts take this matter seriously as well as follow-up with corrective measures, the future looks bleak for all stakeholders.

\section{Introduction}

The violence against doctors, other health care professionals, as well as hospitals is increasing across the globe..$^{1-3}$ This has been documented not only in low- and middle-income countries such as Pakistan, Bangladesh, Mexico, and Sri Lanka but also reported from Italy, United Kingdom, China, India, Australia, and United States ${ }^{1-13}$ Publications also discuss details of the incidents, reasons for the increase, as well as discuss potential ways of mitigating the problem. In countries such as Turkey and Mexico, health care professionals often bear the brunt of the war between police and criminals. ${ }^{11}$ In one such country, over a 4-year period (2012-2015), a total

DOI https://doi.org/10.1055/s-0041-1726137 ISSN 2278-330X.

How to cite this article: Nagpal N, Nagpal N, Kataria N, Parikh P. Violence against Health Care Professionals and Facilities-Local Insights about a Global Malady South Asian J Cancer 2021;9(4):257-260. of 31,767 violent incidents were reported against health care professionals, of which an astounding 18,000 directly involved the doctors at the receiving end. ${ }^{12}$ There are also rare instances of robust government action actually leading to a reduction in the acts of violence against doctors-Spain reporting a $16 \%$ fall since $2012 .{ }^{13}$ However, this is an exception that highlights the grim reality in the rest of the world.

\section{The Situation in Indian}

A retrospective study from India conducted between 2006 and 2017 showed a clearly increasing trend among 100 instances. ${ }^{14}$ The two most vibrant states, Maharashtra

\section{(C) 2021. MedIntel Services Pvt Ltd.}

This is an open access article published by Thieme under the terms of the Creative Commons Attribution-NonDerivative-NonCommercial-License, permitting copying and reproduction so long as the original work is given appropriate credit. Contents may not be used for commercial purposes, or adapted, remixed, transformed or built upon. (https://creativecommons.org/licenses/by-nc-nd/4.0/). Thieme Medical and Scientific Publishers Private Ltd A-12, Second Floor, Sector -2, NOIDA -201301, India 
and National Capital Region reported most acts of violence against health care professionals. The prestigious All India Institute of Medical Sciences, Delhi figured in the top 10 facilities, which was not surprising since more than half (51\%) of incidences involved public or government hospitals. Almost three-fourths (72\%) of attacks were on resident doctors, the most vulnerable frontline professionals. Violence leading to grievous injuries commonly occurred at night and especially in emergency ward. ${ }^{14}$

So, where is the Indian situation different from other countries? We can think of several deplorable and unique problems faced by the Indian health care professional. The Assam tea estate incident is an example of how Dr. Deben Dutta, a senior citizen doctor was beaten to death by workers of the Teok Tea Estate in Jorhat on August 31 last year-the violent mob that even prevented him from being taken to receive emergency medical treatment. ${ }^{15,16}$ Doctors have also been paraded naked or had their faces blackened and even human excreta smeared on them. ${ }^{17,18}$ The incidence in Thane where the sole multispecialty hospital (Singhania Hospital) was razed to rubble because of the death of a political leader is well known. ${ }^{19}$ Patients admitted to the intensive care unit were also not spared. Delicate and expensive medical equipment have been trashed, depriving tens of thousands of patients from the benefit of appropriate investigations and treatment..$^{20-22}$

In the United States and Western Europe, the criminal acts are committed by individual patients (or close relatives), usually under the influence of drugs or alcohol, drugs, or those having a major mental illness. ${ }^{9,23}$ The situation in India is dramatically different. Here, the patient himself or herself is seldom the perpetrator. Instead acts of violence are performed by groups-often involving relatives (other than immediate family members), random unrelated people, or local political leaders (who often call themselves as social workers). ${ }^{24}$ They take the law in their own hands without any fear of reprisal from any authorities. History sheeters or persons with known criminal records are also involved. ${ }^{25,26}$ When such an incident occurs in smaller towns and villages, the sole doctor is left helpless and remains woefully vulnerable to intimidation and even blackmail. When a "spontaneous" group of 100 to 200 people gather "out of the blue" fully equipped to do the most heinous acts of violence, it is clear that this is a deliberate and planned act that systematically uses social media to spread fabricated and twisted misinformation with the primary aim to incite mob fury-often based on vested interests. ${ }^{27-29}$ There are several examples of messages being forwarded on social media about the availability of mobs on hire, especially to get away from paying legitimate hospital dues. There seems to be a tried and tested system whereby paid protestors are available at the drop of the hat and follow instructions, without the slightest of idea as to who is the patient who died or why is the violence being instigated. Whether the men behind such mob violence are motivated by political ambition, turf war, caste, or religious distinctions is for the legal authorities to ascertain, which often does not happen.

This has also been documented in China, the so-called Yi Nao phenomenon. In that country exist mobs that assaults doctors and hospitals, destroy medical equipment, and extort money-all in the name of alleged medical negligence. ${ }^{30-32}$ One Chinese publication documented a 73\% occurrence of Yi Nao among 270 tertiary care hospitals. So, what is the difference between the incidents in China as opposed to India? In China, the main objective of the mob is to gain financially by coercing monetary compensation using the excuse of alleged medical negligence. In India, on the contrary, the primary objective of the mob leaders seems to be flexing of muscles by small time local goons (politicians, religious leaders, and caste "champions") with the aim of gaining publicity and consolidating their hold in their local communities. Here, the financial gain seems to only be a secondary benefit to the perpetrators of the crime. ${ }^{33}$ The sad part is that the Indian mob has no fear of any action, retribution, or punishment from police and other government authorities. For instance, the Karnataka Law Commission reported a total of 173 FIR registered regarding violence against doctors between 2010 and 2017 in that state. ${ }^{34}$ In 39 cases, investigations were still pending and in 101 instances, the trial was pending. Proceedings were completed only in 23 cases, of which there were four convictions with only one culprit actually being penalized. As far as the victim of the violence (doctor) is concerned, not a single one received compensation.

\section{Unrealistic Expectations}

Life expectancy in India has more than doubled since independence. As people get educated, they begin to understand the benefit of technology in tackling hitherto difficult diseases. When stories are exaggerated, expectations rise and become unrealistic. The common man does not pay attention to preventive health or wellness lifestyle. At the same time, they expect doctors and hospitals to cure all ailments-even if they reach hospital late or in critical conditions. Technology contributes $\sim 65 \%$ to the increasing cost of health care. ${ }^{35}$ Relatives often make the statement "kuch bhi karke hamare patient ko bacha lijiye (do anything but save our patient). While free (or highly subsidized) government health care facilities are available to all, only those at the bottom-of-the-pyramid avail of these facilities. The rest opt for treatment in private hospitals because they want more personal attention and the best treatment. When an incurable disease does not respond miraculously, the cost of treatment begins to pinch and they look for all possible avenues to avoid making the payments to the hospital. But this cannot be the reason in the majority of instances where the patient is receiving free treatment in a government health care facility. ${ }^{36}$ In India, health is a state subject. Including the subsidy and allocation from the central government, the total amount spend on health care amounts to only $1.2 \%$ of our country's GDP. ${ }^{37}$ No wonder such free health care facilities are overcrowded, understaffed, and infrastructure is inadequate to deal with the demand. Helplessness and frustration with the systems gets transferred to the most vulnerable person representing the system in front of the patient party. Deficiency in the health care system becomes the justification for violence against health care professionals with allegation of medical negligence becoming the excuse. When public 
hospitals outsource cleaning and other services to the lowest bidder, their staffs have no commitment or incentive to the hospital..$^{38}$ Also, a different person is deployed on day-to-day basis. So, the opportunity for a bond to develop between the patient and the service provider is also lost.

\section{Doctor-Patient Relationship}

Intolerance and rage at the slightest of infarctions is seen globally in several service sectors. However, the doctor and hospital are seen as soft targets. Authorities show alarming reluctance to take action against the perpetrators of the heinous crime. ${ }^{34}$ As a result, violence and abuse remain high mainly against doctors alone. Similar frustration, anger and disappointment by affected persons during canceled flights, collapsed stock market, cheating retainers, or corruption in government offices rarely culminate into violent episodes.

While people may be instigated into taking the law into their own hands, with the excuse that there is no faith in the grievance redressal mechanism provided by the justice system, violence with impunity happens only against doctors and hospitals. This is because patient's relatives and/or members of the accompanying mob feel they are immune from punishment or any retaliatory measures. This is fueled by "breaking news" hungry Indian media that pursue sensationalization and pass "judgment" branding doctors and hospitals guilty of medical negligence, deficiency of service, and malpractice-without any attempt at uncovering the hidden truth. Regional movies and television series are not far behind. Doctors are regularly shown in poor light. ${ }^{39}$ No wonder the trust deficit between the doctors and patients has been eroded gravely..$^{40}$ The grievance redressal mechanism is painted as biased when the conclusion is not in favor of patients.

Patients often use indigenous (AYUSH) and traditional methods of treatment in the initial stages of their illness. ${ }^{41}$ When the disease gets out of hand and become fairly advanced, they arrive at the doorsteps of tertiary hospitals. By this time, they have usually exhausted significant resources, are desperate, and ready to pass on the blame to the first available soft target-the health care professional.

\section{Mob for Hire}

In Kolkata during the year 2018, a single family was found to have been responsible for violence at five diverse hospitals-each time after the death of a patient not related to them. What was discovered was a devious modus operandi. For commercial gains (25\% of the outstanding hospital bills), they would offer their unlawful services. They would then create a ruckus, claim death of "their" patient due to medical negligence, ensure adverse publicity, and coerce the hospital to waive of hospital charges. Proof of their inciting and participating in arson and violence confirmed their crime..$^{26,29,42}$

\section{Next Steps-What the Government Should Do}

Prevention of violence should be a priority with zero tolerance. There are at least 19 states where a legislation to this effect has been notified. Unfortunately, its implementation is anything but enthusiastic. A Central Government Act with a specific IPC number/reference is what is required. Unfortunately, this has not been achieved because of other machinery of the government resisted. ${ }^{43}$ The recent judgment by Jorhat court sentencing the chief perpetrator to death by hanging is the spine that needs to be emulated by all government authorities.

Putting the onus on the doctors is not the way this can be addressed. The victim is not responsible for the solution. Asking doctors to spend more time in counseling and communication will work if there is indeed exists a gap. ${ }^{44} \mathrm{Almost}$ all acts of violence against doctors are due to the urge to avoid paying the legitimate bills, unrealistic expectations, failure to reach the right health care facility in time, and finally, the lesson from past episodes that perpetrators are almost never brought to book-neither the police nor the judiciary taking proactive steps. Instead the concerned criminals are protected and viewed sympathetically since they have lost their near and dear one.

\section{Conclusion}

The indifference feigned by our government and courts will not sweep the problem under the carpet for long. Already a significant number of doctors are giving up their practice to live without the fear of death and violence at the drop of the hat. Future generations are also thinking twice about dedicating their lives to the medical profession..$^{45}$ Long-term effects will be to the detriment of the general public unless serious remedial measures are taken up on a war footing.

Conflict of Interest

None declared.

\section{References}

1 Nagpal N. Incidents of violence against doctors in India: can these be prevented? Natl Med J India 2017;30(2):97-100

2 USA Today op-ed: Violence against Doctors and Nurses due Health Care Dysfunction. Available at: http://www.kevinmd. com/blog/2011/02/usa-today-oped-violence-doctors-nurses -due-health-care-dysfunction.html. Accessed on March 02, 2021

3 Nagpal N, Nagpal N, Kataria N. Is violence against doctors in India a mutation of the global malady. Tropical Ophthalmology 2020;19:31-37

4 Violence against doctors: why China? Why now? What next? Lancet 2014;383(9922):1013

5 Mirza NM, Amjad AI, Bhatti AB, et al. Violence and abuse faced by junior physicians in the emergency department from patients and their caretakers: a nationwide study from Pakistan. J Emerg Med 2012;42(6):727-733

6 Yu Pan, Xiu hong Yang, Jiang Ping He, et al. To be or not to be a doctor, that is the question: a review of serious incidents of violence against doctors in China from 2003-2013. Journal of Public Health 2015;23:111-116

7 Ambesh P. Violence against doctors in the Indian subcontinent: a rising bane. Indian Heart J 2016;68(5):749-750

8 Pitcher G. BMA survey finds one-third of doctors attacked physically or verbally in 2007. Ethics, Health and Safety, HR STRATEGY, Latest News, Occupational Health, Stress, Wellbeing; 2008 
9 Derazon H, Nissimian S, Yosefy C, Peled R, Hay E. [Violence in the emergency department]. Harefuah 1999;137(3-4):95101,175

10 Imran N, Pervez MH, Farooq R, Asghar AR. Aggression and violence towards medical doctors and. nurses in a public health care facility in Lahore, Pakistan: A preliminary investigation. Khyber Med Univ J 2013;5(4):179-184

11 Ferri P, Silvestri M, Artoni C, Di Lorenzo R. Workplace violence in different settings and among various health professionals in an Italian general hospital: a cross-sectional study. Psychol Res Behav Manag 2016;9:263-275

12 Smith M. Rise in violence against doctors in Turkey, elsewhere. CMAJ 2015;187(9):643

13 Ortega Marlasca MM. Tackling violence against health-care workers in Spain. Lancet 2014;384(9947):955

14 Ranjan R, Meenakshi, Singh M, Pal R, Das JK, Gupta S. Epidemiology of violence against medical Practitioners in a developing country (2006-2017). J Health Res Rev 2018;5:153-160

15 Assam: 73-Year-Old Doctor Lynched at Tea Estate, 21 Arrested. Available at: https://www.thehindu.com/news/national/ other-states/assam-court-convicts-25-people-for-lynchingelderly-doctor-in-2019/article32840288.ece. Accessed on March 2, 2021

1625 convicted for lynching Assam Doctor Available at: https://www.thehindu.com/news/national/other-states/ assam-court-convicts-25-people-for-lynching-elderly-doctor-in-2019/article32840288.ece. Accessed on March 2, 2021

17 Mob Assaults Doctor. Smears him with Human Excreta Kolkata News. Available at: https://www.timesofindia.indiatimes.com/ city/kolkata/mob-assaults-doctor-smears-him-with-humanexcreta/articleshow/60294926.cms. Accessed December 28, 2019

18 Mob sets hospital on fire after patients death. Available at: https://www.business-standard.com/article/pti-stories/mobsets-hospital-on-fire-after-patient-s-death-112090900226_1. html/. Accessed December 28, 2019

19 Dighe's death: Sena plans to sue Singhania hospital for `negligence' Available at: https://timesofindia.indiatimes.com/city/ mumbai/dighes-death-sena-plans-to-sue-singhania-hospitalfor-negligence/articleshow/1165652802.cms . Accessed on March 2, 2021

20 Boy dies during treatment irate relatives ransack clinic residence. Available at: https://timesofindia.indiatimes.com/ city/chandigarh/Boy-dies-during-treatment-irate-relativesransack-clinic-residence/articleshow/35135683.cms. Accessed December 31, 2019

21 Mob trashes private Indian Hospital. Available at: https:// www.asiaone.com/News/Latest\%2BNews/Asia/Story/ A1Story20100413-210095.html. Accessed December 30, 2019

22 Kolkata: Mob violently attacks doctors at NRS Hospital after Mohammed Sayeed's death, police mute spectators, allege students. Available at: https://www.opindia.com/2019/06/ kolkata-mob-violently-attacks-doctors-at-nrs-hospital-after-mohammed-sayeeds-death-police-mute-spectators-allege-students/. Accessed on December 30, 2019

23 Hobbs FD. Violence in general practice: a survey of general practitioners' views. BMJ 1991;302(6772):329-332

24 Pakistan I. Angry mob of lawyers attacks hospital causing death of 3 patients. Available at: https://www.npr. org/2019/12/11/787109476/in-pakistan-angry-mob-of-lawyers-attack-hospital-causing-deaths-of-3-patients. Accessed December 31, 2019

25 Angry mobs are attacking doctors at hospitals in India. Available at: https://www.washingtonpost.com/world/asia_ pacific/angry-mobs-are-attacking-doctors-at-hospitals-in-india/2016/05/20/26820fb8-d5c3-11e5-a65b-587e721fb231_ story.html. Accessed December 31, 2019

26 Mob ransacks leading hospital after death local girl. Available at: https://timesofindia.indiatimes.com/city/kolkata/mob-ransacks-leading-hospital-after-death-of-local-girl/articleshow/57177761.cms. Accessed December 31, 2019

27 Ghosh K. Violence against doctors: a wake-up call. Indian J Med Res 2018;148(2):130-133

28 Cop 'Beats Up' Doctor at Sassoon Hospital. Pune. Available at: https://www.indianexpress.com/article/cities/pune/copbeats-up-doctor-at-sassoon-hospital/. Accessed October 16, 2015

29 Mobattacks Kolkatahospitalafter death of babygirl.Availableat: https://timesofindia.indiatimes.com/city/kolkata/mob-attacks-kolkata-hospital-after-death-of-baby-girl/articleshow/67081419.cms. Accessed December 31, 2019

30 Bhattacharya S, Kaushal K, Singh A. Medical violence (Yi Nao phenomenon): its past, present, and future. CHRISMED J Health Res 2018;5:259

31 Tao N. (May 7, 2012). "Hospital violence sign of doctor-patient strife". Shanghai Daily. china.org.cn

32 Hesketh T, Wu D, Mao L, Ma N. Violence against doctors in China. BMJ 2012;345(1):e5730

33 Agarwal SK. Healthcare in India and violence against doctors; the missing links. Indian J Nephrol 2019;29(4):221-231

34 Law commission of Karnataka fourty sixth report pdf available at: https://karunadu.karnataka.gov.in/lawcommission/ Reports/Report\%20No.46.pdf

35 Kumar RK. Technology and healthcare costs. Ann Pediatr Cardiol 2011;4(1):84-86

36 Kapoor MC. Violence against the medical profession. J Anaesthesiol Clin Pharmacol 2017;33(2):145-147

37 National Health Profile. 2019 14th edition: Central Bureau of Health Intelligence, Directorate General Health Services, Ministry of Health and Family Welfare, Government of India. pg 175 Scheme wise Actual Expenditure on NHM/NHM for various Annual Plans (in Rs. Crores)

38 Indian Healthcare Industry Report (November, 2020) Available at: https://www.ibef.org/industry/healthcare-india.aspx

39 Goldacre MJ, Evans J, Lambert TW. Media criticism of doctors: review of UK junior doctors' concerns raised in surveys. BMJ 2003;326(7390):629-630

40 Gopichandran V, Subramaniam S, Kalsingh MJ. COVID-19 pandemic: a litmus test of trust in the health system. Asian Bioeth Rev 2020;1-9

41 Dhankar M. Complementary and alternative medicine: a cross-sectional observational study in pediatric inpatients. J Evid Based Integr Med 2018;23:X18765119

42 For hire protestors to cut hospital bill. Available at: https:// www.telegraphindia.com/india/for-hire-protesters-to-cuthospital-bill/cid/1334873. Accessed December 31, 2019

43 MHA opposition puts bill to check violence against doctors on backburner. Available at: https://economictimes.indiatimes. com/news/ politics-and-nation/mha-opposition-puts-bill-tocheck-violence-against-doctors-on backburner/articleshow/ 72677503. cms?from=mdr. Accessed on March 2, 2021

44 National Health Profile. 2019 14th edition: Central Bureau of Health Intelligence, Directorate General Health Services, Ministry of Health and Family Welfare, Government of India. pg 175 Scheme wise Actual Expenditure on NHM/NHM for various Annual Plans (in Rs. Crores).

45 Parikh PM, Bhosale B, Lokeshwar N, Kamath M, Kumar A, Gulia A, et al. Mediclaim insurance challenges and solutions Doctors supporting patients: A Medic LAWgic initiative. Indian J Med Sci 2019;71(1):22-7 